\title{
Associations between Metabolic Syndrome and Inadequate Sleep Duration and Skipping Breakfast
}

\author{
Nak-Hyun Kim, Dong Heon Shin, Hee-Tae Kim, Su Min Jeong, Su-Yeon Kim, Ki Young Son* \\ Department of Family Medicine, Health Promotion Center, Seoul National University Hospital, Seoul, Korea
}

Background: The prevalence of metabolic syndrome is increasing worldwide, and previous studies have shown that inadequate sleep duration and skipping breakfast may be related to metabolic syndrome. Therefore, we investigated the effects of inadequate sleep and skipping breakfast on metabolic syndrome using data from the Korea National Health and Nutrition Examination Survey (KNHANES) IV \& V reports (2007-2009 and 2010-2012, respectively).

Methods: The sample included 12,999 subjects who participated in the KNHANES IV \& V. Sleep duration and breakfast eating were self-reported, and metabolic syndrome was defined according to the modified National Cholesterol Education Program Adult Treatment Panel III guidelines. Subjects were divided into 12 groups according to breakfast eating and sleep duration patterns, and multiple logistic regression analyses adjusted for age, sex, household income, education level, smoking status, alcohol drinking, physical activity, and total daily energy intake were conducted.

Results: In subjects under 50 years of age, sleeping less than 6 hours was significantly associated with increased metabolic syndrome except among those who ate breakfast on only 1 of the past 2 days. In subjects over 50 years of age, sleeping less than 6 hours was significantly associated with a decreased risk of metabolic syndrome among those who ate breakfast on both days.

Conclusion: In conclusion, significant associations between metabolic syndrome and sleep duration were identified, and these associations differed according to age group.

Keywords: Sleep; Breakfast; Metabolic Syndrome X 


\section{INTRODUCTION}

Metabolic syndrome is currently one of the most important health problems worldwide, owing to its association with the development of type 2 diabetes mellitus and cardiovascular disease (CVD), which can in turn lead to an increased risk of mortality. ${ }^{1,2)}$

The number of people with metabolic syndrome is increasing worldwide, a trend attributed to increasingly sedentary lifestyles and excessive daily caloric intake resulting from rapid socioeconomic growth. ${ }^{3)}$ The age-adjusted prevalence of metabolic syndrome (as defined by the revised National Cholesterol Education Program [NCEP] criteria) for Korea adults participating in the Korea National Health and Nutrition Examination Survey (KNHANES) was $31.3 \%$ in $2007 .{ }^{4}$ )

Several previous epidemiologic studies have shown that sleep duration may be an important risk factor for metabolic syndrome. For example, Choi et al. ${ }^{5)}$ conducted a study using data from the KNHANES 2001, and reported a U-shaped association between sleep duration and metabolic syndrome. In other words, both short ( $<7$ hours) and long ( $\geq 9$ hours) sleep durations have been associated with increased risks of morbidity and mortality related to metabolic syndrome. ${ }^{\text {) }}$

Likewise, several previous studies have shown that skipping breakfast may also increase the risk of metabolic syndrome. ${ }^{7)}$ For example, Smith et al. ${ }^{8)}$ reported a larger waist circumference, higher fasting insulin, and increased low density lipoprotein cholesterol levels in participants who skipped breakfast. However, results regarding this relationship conflict, as some studies have not found a significant association between skipping breakfast and metabolic syndrome. ${ }^{9}$ Furthermore, Min et al..$^{7}$ reported that regularly eating breakfast actually increased the risk of elevated serum triglyceride levels.

Therefore, both sleep duration and breakfast eating appear to be important contributors to the incidence of metabolic syndrome. In addition, several studies have shown that skipping breakfast is associated with reduced sleep duration. ${ }^{10,11)}$ indicating possible interactions between the two.

Therefore, in this study, we investigated the effects of inadequate sleep and skipping breakfast on metabolic syndrome using data from the KNHANES IV \& V (2007-2012).

\section{METHODS}

\section{Study Subjects}

The KNHANES is conducted by the Korean Ministry of Health and Welfare every 2 years. For this study, data from the KNHANES IV \& V, which included a total of 50,405 participants, was analyzed. Subjects who (1) were under 20 years of age $(n=12,801)$, (2) had incomplete data about metabolic syndrome components $(\mathrm{n}=15,364)$, (3) did not answer questions about daily sleep du- ration and breakfast eating habits $(\mathrm{n}=2,834)$, (4) had taken medication for hypertension, diabetes mellitus, or dyslipidemia $(\mathrm{n}=$ $4,308)$, or (5) had incomplete data for other variables $(n=2,099)$, were excluded. Finally, a total of 12,999 participants were included in this study.

\section{Measures}

1) Anthropometric and laboratory measurements

Weight and height were measured with participants in light clothing and no shoes. The body mass index (BMI) was calculated as weight $(\mathrm{kg})$ divided by the square of height $\left(\mathrm{m}^{2}\right)$. Waist circumference was measured at the narrowest point between the last rib and the iliac crest. Three blood pressure (BP) measurements were taken with the patient in a sitting position after a rest period of at least 5 minutes. The second and third systolic and diastolic BP measures were averaged for the analysis. Blood samples were taken in the morning after at least 8 hours of fasting. All blood samples were taken on the same day. Further details regarding the KNHANES IV \& V are described in a study by Lee et al. ${ }^{12)}$

\section{2) Assessment of sleep duration and breakfast eating}

Sleep duration and breakfast eating were self-reported. Sleep duration was based on responses to the question "how many hours do you usually sleep each day?" Participants responded by reporting the number of hours they slept. Eating breakfast during the previous 2 days was based on responses to the question, "did you eat every meal for the last two days?" Response options included "yes" and "no."

\section{3) Metabolic syndrome}

The definition of metabolic syndrome was taken from the modified NCEP Adult Treatment Panel III guidelines. Metabolic syndrome was considered present if three or more of the following five criteria were met: (1) central obesity (i.e., a waist circumference $\geq 90 \mathrm{~cm}$ for men or $\geq 85 \mathrm{~cm}$ for women); (2) hypertriglyceridemia with fasting plasma triglyceride levels $\geq 1.69$ $\mathrm{mmol} / \mathrm{L}$ (150 mg per $100 \mathrm{~mL}$ ); (3) decreased levels of high density lipoprotein (HDL) cholesterol with fasting HDL cholesterol levels $\leq 1.04 \mathrm{mmol} / \mathrm{L}$ (40 mg per $100 \mathrm{~mL}$ ) for men and $\leq 1.29$ $\mathrm{mmol} / \mathrm{L}$ (50 mg per $100 \mathrm{~mL}$ ) for women; (4) hypertension with systolic or diastolic BP $\geq 130 / 85 \mathrm{~mm} \mathrm{Hg}$; and (5) hyperglycemia with fasting plasma glucose $\geq 5.6 \mathrm{mmol} / \mathrm{L}$ ( $100 \mathrm{mg}$ per 100 $\mathrm{mL})$.

\section{4) Other variables}

The risk of developing an alcohol use disorder was defined by the National Institute on Alcohol Abuse and Alcoholism. For women, low-risk drinking is defined as having no more than three drinks on any single day and no more than seven drinks per week; for men, it is defined as no more than four drinks on 
any single day and no more than 14 drinks per week. Household income and education level were self-reported. Household income was divided into four quartile groups while education level was classified into three categories: elementary school, middle school to high school, and university or higher. Self-reported physical activity was converted into metabolic activity and categorized into three groups according to the International Physical Activity Questionnaire guidelines: low, moderate, and high. Total caloric intake and the proportion of energy from carbohydrates, proteins and fats were also estimated.

\section{Statistics}

Differences between the normal and metabolic syndrome groups were compared using a $\chi^{2}$ and Student t-test for categorical and continuous variables, respectively. Multiple logistic regression analyses were used to examine the association of sleep duration and breakfast eating with metabolic syndrome according to age group. We divided study subjects into 12 groups according to three categories of breakfast eating with four categories of sleep duration. All data are shown as numbers, percentages, mean \pm standard deviation, odds ratios (ORs), and 95\% confidence intervals (CIs). $\mathrm{P}<0.05$ was considered statistically sig- nificant. All statistical analyses were performed using STATA ver. 13.1 software (Stata Co., College Station, TX, USA).

\section{RESULTS}

\section{Participant Characteristics}

The basic characteristics of the study subjects according to metabolic syndrome status are presented in Table 1. Among the total sample $(n=12,999), 40.8 \%(n=5,308)$ of participants were male and $59.2 \%(n=7,691)$ were female. The mean age was $45.5 \pm 14.9$ years. About $15.9 \%(n=2,065)$ were diagnosed with metabolic syndrome. A higher proportion of men $(n=1,066$ / $5,308,20.1 \%)$ than women $(n=999 / 7,691,13.0 \%)$ had metabolic syndrome, and subjects with metabolic syndrome tended to be older. The percentage of subjects over 50 years was higher in the group with metabolic syndrome $(n=1,126 / 2,065,54.5 \%)$ compared to the normal group $(\mathrm{n}=3,635 / 10,934,33.2 \%$; $<<0.001)$. Metabolic syndrome was associated with sex, sleep duration, breakfast eating, household income, education level, BMI, smoking status, and alcohol drinking $(\mathrm{P}<0.001$ for all variables). However, metabolic syndrome was not significantly associated with physical activity or total daily caloric intake $(\mathrm{P}=0.246$ and $\mathrm{P}=$ 0.044 , respectively).

Table 1. Basic characteristics of study populations $(n=12,999)$

\begin{tabular}{|c|c|c|c|c|}
\hline Characteristic & Category & Normal $(n=10,934)$ & Metabolic syndrome $(n=2,065)$ & P-value* \\
\hline Age (y) & $\begin{array}{l}20-50 \\
\geq 50\end{array}$ & $\begin{array}{l}7,299(88.60) \\
3,635(76.35)\end{array}$ & $\begin{array}{r}939(11.40) \\
1,126(23.65)\end{array}$ & $<0.001$ \\
\hline Sex & $\begin{array}{l}\text { Male } \\
\text { Female }\end{array}$ & $\begin{array}{l}4,242(79.92) \\
6,692(87.01)\end{array}$ & $\begin{array}{r}1,066(20.08) \\
999(12.99)\end{array}$ & $<0.001$ \\
\hline Sleep duration (h) & $\begin{array}{l}<6 \\
6-7 \\
7-8 \\
\geq 8\end{array}$ & $\begin{array}{l}1,284(80.25) \\
2,830(84.25) \\
3,352(84.97) \\
3,468(84.69)\end{array}$ & $\begin{array}{l}316(19.75) \\
529(15.75) \\
593(15.03) \\
627(15.31)\end{array}$ & $<0.001$ \\
\hline Breakfast eating & $\begin{array}{l}2 \\
1 \\
0\end{array}$ & $\begin{array}{l}8,281(83.41) \\
1,051(87.08) \\
1,602(85.94)\end{array}$ & $\begin{array}{r}1,647(16.59) \\
156(12.92) \\
262(14.06)\end{array}$ & $<0.001$ \\
\hline Household income (quartile) & $\begin{array}{l}\text { 1st } \\
\text { 2nd } \\
\text { 3rd } \\
\text { 4th }\end{array}$ & $\begin{array}{l}3,360(87.05) \\
3,276(85.25) \\
2,672(83.37) \\
1,626(77.26)\end{array}$ & $\begin{array}{l}500(12.95) \\
567(14.75) \\
533(16.63) \\
465(22.24)\end{array}$ & $<0.001$ \\
\hline Education level & $\begin{array}{l}\text { Low } \\
\text { Intermediate } \\
\text { High }\end{array}$ & $\begin{array}{l}1,931(73.70) \\
5,310(85.30) \\
3,693(88.90)\end{array}$ & $\begin{array}{l}689(26.30) \\
915(14.70) \\
461(11.10)\end{array}$ & $<0.001$ \\
\hline Obesity (BMI) & $\begin{array}{l}\text { Normal }\left(\mathrm{BMl}<25 \mathrm{~kg} / \mathrm{m}^{2}\right) \\
\text { Obese }\left(\mathrm{BMl} \geq 25 \mathrm{~kg} / \mathrm{m}^{2}\right)\end{array}$ & $\begin{array}{l}8,726(92.36) \\
2,208(62.18)\end{array}$ & $\begin{array}{c}722(7.64) \\
1,343(37.82)\end{array}$ & $<0.001$ \\
\hline Smoking status & $\begin{array}{l}\text { Current smoker } \\
\text { Ex-smoker } \\
\text { Non-smoker }\end{array}$ & $\begin{array}{l}2,315(80.75) \\
1,874(79.68) \\
6,745(86.70)\end{array}$ & $\begin{array}{r}552(19.25) \\
478(20.32) \\
1,035(13.30)\end{array}$ & $<0.001$ \\
\hline Alcohol drinking & $\begin{array}{l}\text { Low risk } \\
\text { High risk }\end{array}$ & $\begin{array}{l}9,797(85.36) \\
1,137(74.70)\end{array}$ & $\begin{array}{r}1,680(14.64) \\
385(25.30)\end{array}$ & $<0.001$ \\
\hline Physical activity & $\begin{array}{l}\text { Low } \\
\text { Moderate } \\
\text { High }\end{array}$ & $\begin{array}{r}8,178(83.83) \\
2,349(85.17) \\
407(83.74)\end{array}$ & $\begin{array}{r}1,577(16.17) \\
409(14.83) \\
79(16.26)\end{array}$ & 0.246 \\
\hline Total daily energy intake (kcal) & & $1,934.65 \pm 827.74$ & $1,975.14 \pm 881.15$ & 0.044 \\
\hline
\end{tabular}

Values are presented as number (\%).

BMl, body mass index calculated as weight in kilograms divided by height in meters squared.

*From a t-test for continuous variables and $\chi^{2}$ test for categorical variables comparing a difference between normal group and metabolic syndrome group. 
Table 2. Analyses of sleep duration and breakfast eating with metabolic syndrome according to age*

\begin{tabular}{|c|c|c|c|c|c|}
\hline \multirow{2}{*}{ Variable } & \multirow{2}{*}{$\begin{array}{l}\text { Breakfast eating } \\
\text { last } 2 \text { days }\end{array}$} & \multicolumn{4}{|c|}{ Sleep duration (y) } \\
\hline & & $<6$ & $6-7$ & $7-8$ & $\geq 8$ \\
\hline \multirow[t]{3}{*}{ Total subjects } & 2 & $0.926(0.776-1.106)$ & $0.979(0.844-1.135)$ & 1.000 & $1.002(0.870-1.155$ \\
\hline & 1 & $1.247(0.769-2.020)$ & $1.199(0.868-1.658)$ & $1.091(0.777-1.533)$ & $0.824(0.579-1.174$ \\
\hline & 0 & 1.519 (1.040-2.218) & $1.141(0.859-1.514)$ & $1.177(0.897-1.546)$ & $1.191(0.914-1.553$ \\
\hline \multirow[t]{3}{*}{ Age $<50$ y } & 2 & $1.429(1.051-1.943)$ & $1.022(0.820-1.273)$ & 1.000 & $0.976(0.782-1.218$ \\
\hline & 1 & $1.626(0.840-3.148)$ & $1.440(0.976-2.124)$ & $1.283(0.862-1.911)$ & $0.928(0.602-1.431$ \\
\hline & 0 & $1.731(1.036-2.894)$ & $1.350(0.978-1.864)$ & $1.214(0.876-1.683)$ & $1.443(1.047-1.990$ \\
\hline \multirow[t]{3}{*}{ Age $\geq 50 y$} & 2 & $0.791(0.636-0.983)$ & $0.902(0.738-1.103)$ & 1.000 & $1.137(0.943-1.372$ \\
\hline & 1 & $1.002(0.496-2.026)$ & $0.721(0.379-1.375)$ & $0.814(0.385-1.722)$ & $0.963(0.496-1.873$ \\
\hline & 0 & $1.309(0.735-2.330)$ & $0.544(0.252-1.171)$ & $1.459(0.816-2.607)$ & $1.174(0.678-2.031)$ \\
\hline
\end{tabular}

Values are presented as odds ratio (95\% confidence interval).

*Multiple logistic regression, adjusted for age, sex, household income, education level, smoking status, alcohol drinking, physical activity, and total daily energy intake.

\section{Sleep Duration and Breakfast Eating by Age}

Analyses of sleep duration and breakfast eating with metabolic syndrome according to age group revealed that among all subjects, skipping breakfast on both of the days prior to the survey and sleeping less than 6 hours showed a significant association with increased metabolic syndrome (adjusted OR [aOR], 1.519; 95\% CI, 1.040-2.218). In subjects under 50 years of age, sleeping less than 6 hours was significantly associated with increased metabolic syndrome in all groups except those who ate breakfast on only 1 day (group who ate breakfast on both days: aOR, 1.429; 95\% CI, 1.051-1.943; group who skipped breakfast on both days: aOR, 1.731; 95\% CI, 1.036-2.894). The group who skipped breakfast for both days and slept more than 8 hours also showed an increased risk of metabolic syndrome. In subjects over 50 years of age, those who ate breakfast on both days and slept less than 6 hours had a decreased risk of metabolic syndrome (aOR, 0.791; 95\% CI, 0.636-0.983). Further information is shown in Table 2.

\section{DISCUSSION}

We found that only the group who skipped breakfast on both days and slept less than 6 hours had an increased risk of metabolic syndrome after adjusting for possible confounding variables.

Similar results were reported by Kim et al. ${ }^{13)}$ who found that disrupted eating patterns exacerbated the development of obesity and metabolic disease in short sleepers. The authors explained that these results may be because of poor nutritional composition and altered physiological responses to nutrients. Likewise, we could also infer that there were some additive effects of short sleep and skipping breakfast on metabolic syndrome in this study.

In the group of participants under 50 years of age, sleeping less than 6 hours was associated with an increased risk of metabolic syndrome, except for those who reported eating breakfast on only 1 day. However, the number of participants who slept less than 6 hours and ate breakfast on only 1 day was very small ( $n=76 / 8,238,0.92 \%)$ and may have limited the statistical power. A larger cell size might increase the power and reveal results similar to those found in other groups who slept less than 6 hours.

In the group of participants over 50 years of age, sleeping less than 6 hours and eating breakfast on both days was associated with a decreased risk of metabolic syndrome. There are several possible explanations for these findings. First, many studies examining the association between sleep duration and metabolic syndrome showed that long sleepers had an increased risk of metabolic syndrome, while short sleepers did not even after adjusting for confounding variables. ${ }^{14)}$ Second, short sleep duration may be mediated by napping. For example, Cohen-Mansfield and Perach ${ }^{15)}$ showed that short nighttime sleep had a protective effect on mortality for those who nap during the day. However, in our study, information about daytime napping status was not collected. Therefore, future studies examining the association between sleep duration and metabolic syndrome should be include napping status.

The analysis stratified by age group showed that the results varied by age group. One possible explanations is that factors more important than sleep duration and breakfast eating, such as noninfectious inflammation, may be associated with an increased risk of metabolic syndrome among older age groups. Furthermore these additional factors may not be important for younger age groups. For example, Villareal et al. ${ }^{16)}$ reported that noninfectious inflammation is associated with advanced age and relevant to the pathogenesis of CVD, insulin resistance, and type 2 diabetes. In addition, many previous studies have shown these diseases to be closely associated with metabolic syndrome. ${ }^{17)}$ Therefore it is possible that factors such as noninfectious inflammation, as compared to sleep duration or breakfast eating, might also have had strong associations with metabolic syndrome in this study, particularly among the older age group. Thus, we cannot exclude potential associations between breakfast eating or sleep duration and additional factors, and more studies regarding these associations are necessary.

Our study had several limitations. First, this was cross-sec- 
tional study design using KNHANES data; therefore, we cannot identify casual relationships between variables. However, as described above, many other studies have reported an association between metabolic syndrome and inadequate sleep duration as well as skipping breakfast.

Second, participants only reported if they had skipped breakfast on the previous 2 days, and the skipping breakfast group was defined as those who had skipped breakfast at least 1 day. Therefore, it is possible that the proportion of individuals in the group that skipped breakfast was overestimated. However, the 2012 National Health Statistics reported by the Korean Ministry of Health and Welfare, also defined the breakfast-skipping group as participants who had skipped breakfast on at least 1 day. In addition, no significant differences were found between analyses conducted using those who skipped breakfast on at least 1 day and those who skipped breakfast on both days.

Third, data about sleep duration and breakfast eating were collected from self-reported questionnaires; therefore, there is a potential for recall bias in our study. Finally, we did not have data regarding sleep quality, which is an important measure because the same amount of sleep can have different effects depending on its quality. For example, Kristen et al. reported that both sleep duration and quality were significant markers of glycemic control. ${ }^{18)}$ Therefore further studies to determine the effects of sleep duration and sleep quality are necessary.

In conclusion, this study identified significant associations between metabolic syndrome and sleep duration, and these associations differed according to age group.

\section{CONFLICT OF INTEREST}

No potential conflict of interest relevant to this article was reported.

\section{REFERENCES}

1. Lakka HM, Laaksonen DE, Lakka TA, Niskanen LK, Kumpusalo E, Tuomilehto J, et al. The metabolic syndrome and total and cardiovascular disease mortality in middle-aged men. JAMA 2002;288:2709-16.

2. Ford ES, Giles WH, Dietz WH. Prevalence of the metabolic syndrome among US adults: findings from the third National Health and Nutrition Examination Survey. JAMA 2002;287:356-9.

3. Park HS, Oh SW, Cho SI, Choi WH, Kim YS. The metabolic syndrome and associated lifestyle factors among South Korean adults. Int J Epidemiol 2004;33:328-36.

4. Lim S, Shin H, Song JH, Kwak SH, Kang SM, Won Yoon J, et al. Increas- ing prevalence of metabolic syndrome in Korea: the Korean National Health and Nutrition Examination Survey for 1998-2007. Diabetes Care 2011;34:1323-8.

5. Choi KM, Lee JS, Park HS, Baik SH, Choi DS, Kim SM. Relationship between sleep duration and the metabolic syndrome: Korean National Health and Nutrition Survey 2001. Int J Obes (Lond) 2008;32:1091-7.

6. Basner M, Fomberstein KM, Razavi FM, Banks S, William JH, Rosa RR, et al. American time use survey: sleep time and its relationship to waking activities. Sleep 2007;30:1085-95.

7. Min C, Noh H, Kang YS, Sim HJ, Baik HW, Song WO, et al. Skipping breakfast is associated with diet quality and metabolic syndrome risk factors of adults. Nutr Res Pract 2011;5:455-63.

8. Smith KJ, Gall SL, McNaughton SA, Blizzard L, Dwyer T, Venn AJ. Skipping breakfast: longitudinal associations with cardiometabolic risk factors in the Childhood Determinants of Adult Health Study. Am J Clin Nutr 2010;92:1316-25.

9. Li Y, Nemoto T, Tobimatsu S, Saito M, Ebata M, Munakata H, et al. Relationship between skipping breakfast and impaired fasting glucose along with cardiovascular and pre-diabetes condition risk factors in apparently healthy subjects. Endocrinol Stud 2011;1:76-80.

10. Sajjad A, Anwer Mo, Anwer S, Zaidi SA, Hasan A. Missing breakfast, sleep and exercise: are you skipping out years of life. J Nutr Health Sci 2014;1:1-7.

11. Keski-Rahkonen A, Kaprio J, Rissanen A, Virkkunen M, Rose RJ. Breakfast skipping and health-compromising behaviors in adolescents and adults. Eur J Clin Nutr 2003;57:842-53.

12. Lee BK, Kim Y, Kim YI. Association of serum ferritin with metabolic syndrome and diabetes mellitus in the South Korean general population according to the Korean National Health and Nutrition Examination Survey 2008. Metabolism 2011;60:1416-24.

13. Kim S, DeRoo LA, Sandler DP. Eating patterns and nutritional characteristics associated with sleep duration. Public Health Nutr 2011;14: 889-95.

14. Youngstedt SD, Kripke DF. Long sleep and mortality: rationale for sleep restriction. Sleep Med Rev 2004;8:159-74.

15. Cohen-Mansfield J, Perach R. Sleep duration, nap habits, and mortality in older persons. Sleep 2012;35:1003-9.

16. Villareal DT, Miller BV 3rd, Banks M, Fontana L, Sinacore DR, Klein S. Effect of lifestyle intervention on metabolic coronary heart disease risk factors in obese older adults. Am J Clin Nutr 2006;84:1317-23.

17. Alexander CM, Landsman PB, Teutsch SM, Haffner SM; Third National Health and Nutrition Examination Survey (NHANES III); National Cholesterol Education Program (NCEP). NCEP-defined metabolic syndrome, diabetes, and prevalence of coronary heart disease among NHANES III participants age 50 years and older. Diabetes 2003;52:1210-4.

18. Knutson KL, Ryden AM, Mander BA, Van Cauter E. Role of sleep duration and quality in the risk and severity of type 2 diabetes mellitus. Arch Intern Med 2006;166:1768-74. 